\title{
Caveolin-1-eNOS signaling promotes p190RhoGAP-A nitration and endothelial permeability
}

\author{
M. Rizwan Siddiqui, ${ }^{1,2}$ Yulia A. Komarova, ${ }^{1,2}$ Stephen M. Vogel, ${ }^{1,2}$ Xiaopei Gao, ${ }^{1,2}$ Marcelo G. Bonini, ${ }^{1,2}$ \\ Johnson Rajasingh, ${ }^{1,2}$ You-Yang Zhao, 1,2 Viktor Brovkovych,, ${ }^{1,2}$ and Asrar B. Malik',2 \\ 'Department of Pharmacology and ${ }^{2}$ Center for Lung and Vascular Biology, University of Illinois College of Medicine, Chicago, IL 60612
}

$\mathrm{E}$ ndothelial barrier function is regulated by adherens junctions (AJs) and caveolae-mediated transcellular pathways. The opening of $A \mathrm{~J}$ s that is observed in caveolin- $\left.1^{-/-}\left(\mathrm{Cav}^{-1}\right)^{-/-}\right)$endothelium suggests that Cav-1 is necessary for $\mathrm{AJ}$ assembly or maintenance. Here, using endothelial cells isolated from Cav-1 ${ }^{-1-}$ mice, we show that $\mathrm{Cav}^{-1}$ deficiency induced the activation of endothelial nitric oxide synthase (eNOS) and the generation of nitric oxide (NO) and peroxynitrite. We assessed S-nitrosylation and nitration of $\mathrm{AJ}$-associated proteins to identify downstream NO redox signaling targets. We found that the
GTPase-activating protein (GAP) p190RhoGAP-A was selectively nitrated at Tyr1105, resulting in impaired GAP activity and RhoA activation. Inhibition of eNOS or RhoA restored $A J$ integrity and diminished endothelial hyperpermeability in $\mathrm{Cav}^{-1}{ }^{-/-}$mice. Thrombin, a mediator of increased endothelial permeability, also induced nitration of p120-catenin-associated p190RhoGAP-A. Thus, eNOS-dependent nitration of p190RhoGAP-A represents a crucial mechanism for AJ disassembly and resultant increased endothelial permeability.

\section{Introduction}

The endothelium lining all blood vessels plays an essential role in the maintenance of tissue fluid homeostasis (Mehta and Malik, 2006). It finely controls the permeability of the vessel wall barrier to plasma proteins and small solutes via transcellular, caveolae-mediated transcytosis and paracellular, inter-endothelial junctional (IEJ) routes. Whereas IEJs are permeant to molecules with radii of $3 \mathrm{~nm}$ or less, caveolae-mediated vesicle trafficking transports different-sized plasma proteins across the vascular barrier (Michel, 1996). The interrelationships between paracellular and transcellular pathways are not well understood. The loss of caveolin-1 (Cav-1) results in not only disappearance of caveolar structures but also destabilization of IEJs and formation of inter-endothelial gaps (Schubert et al.,

M.R. Siddiqui and Y.A. Komarova contributed equally to this paper. Correspondence to Asrar B. Malik: abmalik@uic.edu

Abbreviations used in this paper: $\mathrm{A}$, adherens junction; $\mathrm{AP}$, antennapedia; Cav-1, caveolin-1; CSD, Cav-1 scaffolding domain; DHE, dihydroethidium EBA, Evans blue albumin; eNOS, endothelial nitric oxide synthase; GAP GTPase-activating protein; HPAEC, human pulmonary artery endothelial cell; IEJ, inter-endothelial junction; L-NNA, nitro-l-arginine; MLC, myosin light chain MLVEC, murine lung vascular endothelial cell; NPA, N-propyl--arginine; PEG $\mathrm{SOD}$, polyethylene glycol-superoxide dismutase; SIN-1, 3-morpholinosydnonimine SNO, S-nitrosothiol; TEMPOL, 4-hydroxy-2,2,6,6-tetramethylpiperidinyloxy; $\mathrm{Wt}$, wild type.

The Rockefeller University Press $\$ 30.00$
2002; Miyawaki-Shimizu et al., 2006). We surmised from these previous studies that opening of the paracellular route for albumin transport in $\mathrm{Cav}-\mathrm{I}^{-/-}$mice might represent a general mechanism by which Cav-1 influences IEJs and regulates junctional integrity.

In addition to the transport of plasma proteins and lipids, caveolae compartmentalize signaling molecules within lipid raft microdomains (García-Cardeña et al., 1997). Cav-1 interacts with a variety of signaling molecules such as EGF receptor (EGFR), c-Src, phosphoinositide 3-kinase (PI3K), G $\alpha_{i}$, and endothelial nitric oxide synthase (eNOS; also known as NOS type 3), and binding of proteins to Cav-1 often leads to their inactivation (Minshall et al., 2002; Mehta and Malik, 2006). Interestingly, eNOS inhibitors were shown to restore the increase in paracellular permeability observed in Cav-1-deficient mice (Miyawaki-Shimizu et al., 2006), which suggests that eNOS activity is required for the opening of IEJs. In the present study, we addressed mechanisms by which eNOS-dependent redox

(C) 2011 Siddiqui et al. This article is distributed under the terms of an AttributionNoncommercial-Share Alike-No Mirror Sites license for the first six months after the publication date (see http://www.rupress.org/terms). After six months it is available under a Creative Commons License (Attribution-Noncommercial-Share Alike 3.0 Unported license, as described at http://creativecommons.org/licenses/by-nc-sa/3.0/). 
a
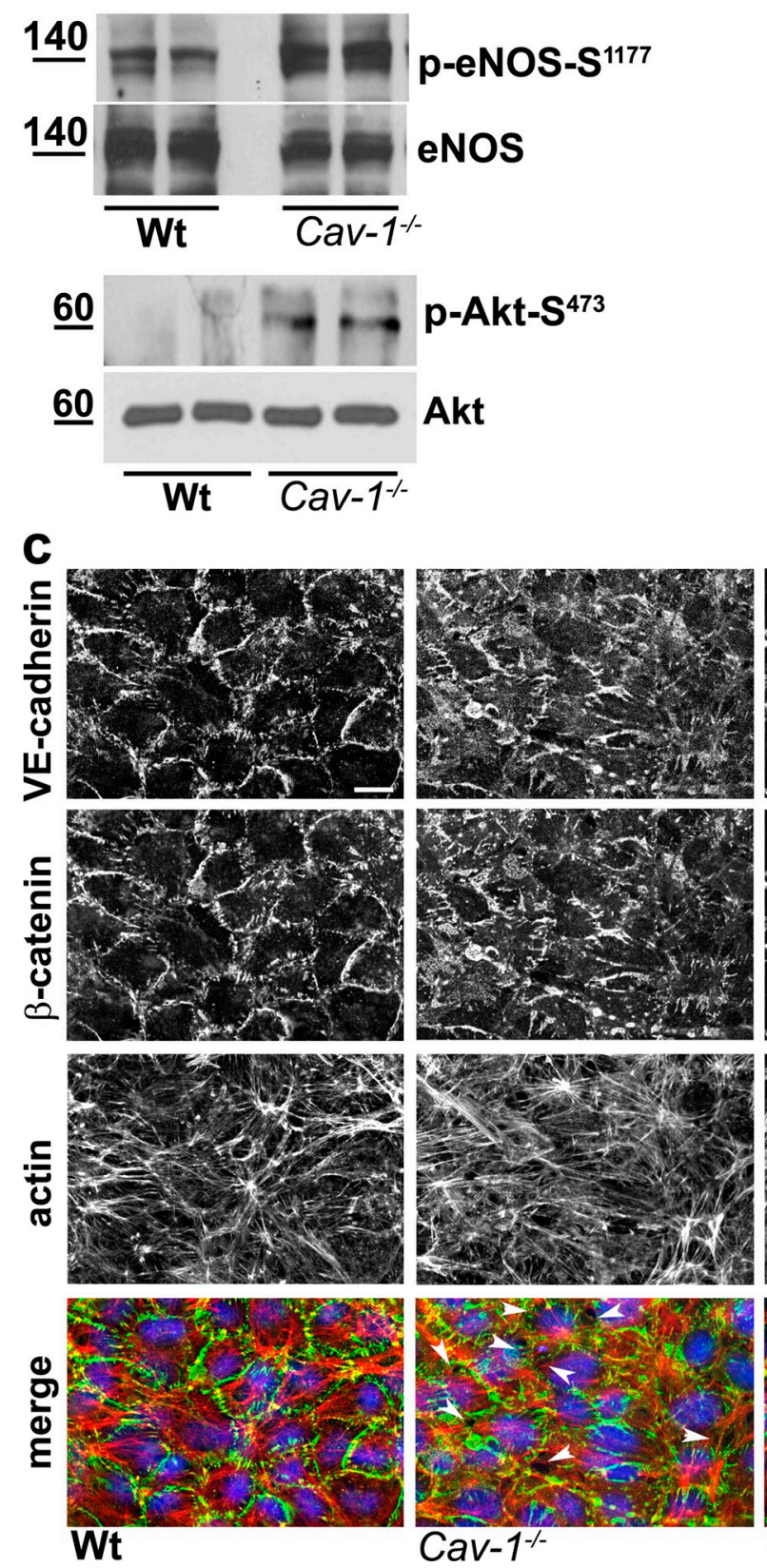

Cav-1 ${ }^{-1-}$
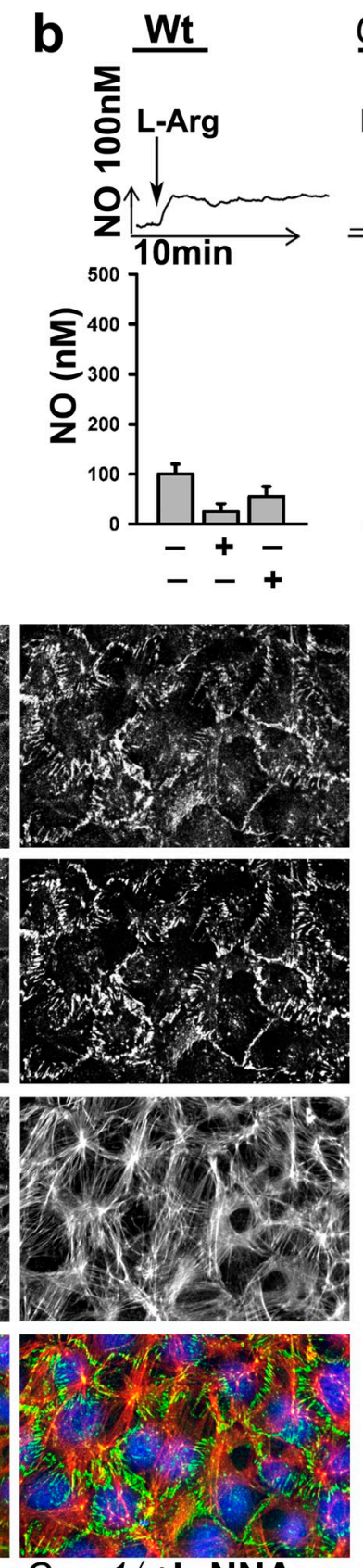

Cav-1 ${ }^{-1}+\mathrm{L}-\mathrm{NNA}$
Cav-1-1-
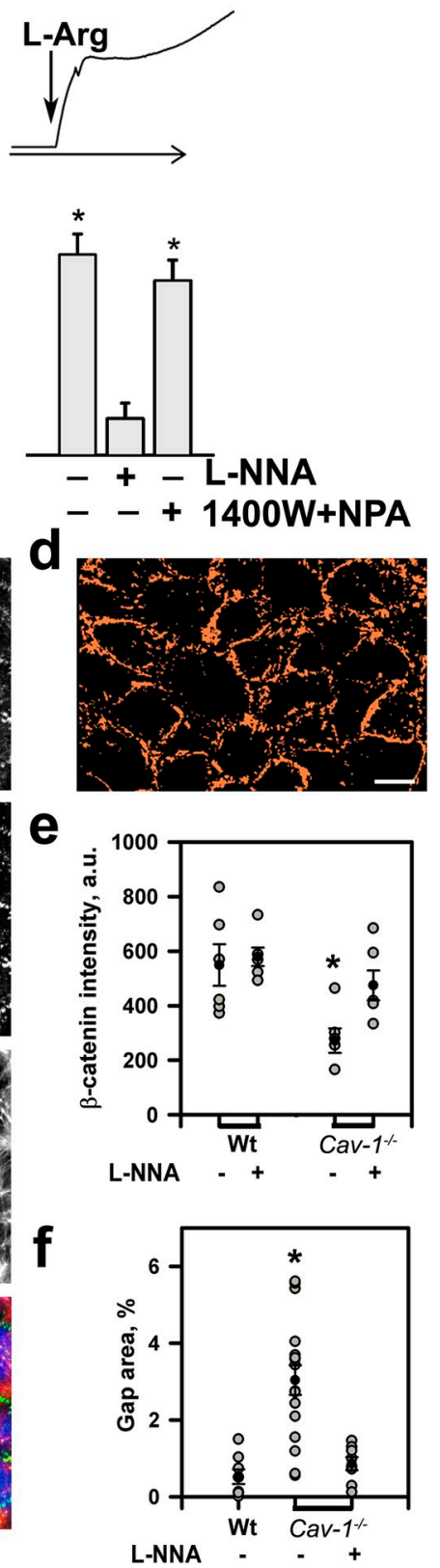

Figure 1. Cav-1 deficiency induces eNOS activation and AJ destabilization in endothelium. (a) Phosphorylation of eNOS at $\mathrm{S}^{1177}$ and $\mathrm{Akt}-1$ at $\mathrm{S}^{473}$ in $\mathrm{Wt}$

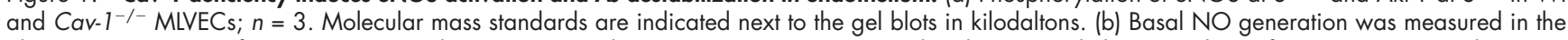
absence or presence of l-NNA or NPA and 1400W in combination. Arrow, t-arginine replenishment. Scale bars are shown for $100 \mathrm{nM}$ NO and 10 min. Bar plot, NO accumulation in a media over 20 min; mean \pm SEM (error bars); ${ }^{*}, \mathrm{P}<0.05$ as compared with Wt control; $n=6$. (c) Wt and Cav- $7^{-1-}$ endothelial monolayers stained for VE-cadherin, $\beta$-catenin (green in overlays), F-actin (red), and nuclei (blue). Inter-endothelial gaps in Cav- $7^{-1-}$ monolayers are indicated by arrowheads. Bar, $10 \mu \mathrm{m}$. (d and e) Accumulation of $\beta$-catenin at Als was expressed as a mean pixel intensity of threshold area shown in $d$ (threshold above intracellular background is in orange). (f) Area of inter-endothelial gaps was determined using the same set of images as in $e ; n=17$. Black circles and error bars in e and $f$ indicate mean and SEM, respectively; ${ }^{*}, \mathrm{P}<0.01$ as compared with $\mathrm{W}_{t}$ control.

signaling, which is normally held in abeyance by binding of eNOS to Cav-1 (Bucci et al., 2000), regulates IEJ integrity and thereby the permeability of the endothelial barrier.

\section{Results and discussion}

We first determined basal eNOS activity in murine lung vascular endothelial cells (MLVECs) isolated from wild-type (Wt) and
Cav-1 $1^{-1-}$ mice (Fig. S1). We observed an approximately twofold increase in eNOS phosphorylation at $\mathrm{S}^{1177}$ (Fig. 1 a), the Akt-1 phosphorylation site known to regulate enzymatic activity of eNOS (Dimmeler et al., 1999). Phosphorylation of Akt-1 at $S^{473}$ was also increased (Fig. 1 a), which indicates marked Akt-1 activation in $\mathrm{Cav}_{-1}^{-1-}$ endothelium. Basal nitric oxide (NO) generation determined by L-arginine replenishment was fourfold greater in $\mathrm{Cav}_{-1}^{-1-}$ MLVECs (Fig. 1 b). This finding 
is consistent with the reported increased plasma NO concentration in Cav-1-deficient mice (Miyawaki-Shimizu et al., 2006). Nitro-L-arginine (L-NNA) treatment at an inhibitory concentration for nNOS, and eNOS prevented NO generation, whereas treatment with $1400 \mathrm{~W}$ and $N$-propyl-L-arginine (NPA) in combination (at inhibitory concentrations for iNOS and nNOS) had a marginal effect (Fig. 1 b). We concluded that Cav-1 deficiency in the endothelium resulted in Akt-1 and eNOS activation and an augmented NO production, which is in agreement with the role of Cav-1 in inhibiting eNOS activity in endothelium (García-Cardeña et al., 1997).

Next we determined the effects of Cav-1 deficiency on adherens junction (AJ) integrity, the primary adhesive complex in the continuous endothelium responsible for regulating junctional permeability. We did not observe any significant change in the expression of AJ proteins in $\mathrm{Cav}-1^{-1-}$ MLVECs compared with Wt cells (Fig. S1 b), which is in contrast to the difference reported for the brain endothelial cells (Song et al., 2007). This inconsistency might reflect tissue specificity (i.e., continuous vs. the highly restrictive brain endothelial barrier). Whereas AJs play a primary role in the mechanism of AJ integrity in the continuous endothelium, they are secondary in maintaining brain-blood barrier function (Nitta et al., 2003). Integrity of AJs was assessed by immunofluorescent staining for VE-cadherin, the homotypic adhesive protein of AJs (Corada et al., 1999), and $\beta$-catenin. Both proteins accumulated at the cell border; however, clustering of VE-cadherin at the cell surface of $\mathrm{Cav}-1^{-1-}$ endothelium was markedly reduced (Fig. $1 \mathrm{c}$ ). VE-cadherin formed discrete patches on the $\mathrm{Cav}-1^{-/-}$endothelial cell surface; in contrast, VE-cadherin was organized as bands encircling the Wt endothelial cells. Accumulation of $\beta$-catenin at AJs, also used to assess AJ integrity, was significantly reduced in $\mathrm{Cav}-1^{-/-}$endothelium (Fig. 1, c-e). Cav-1 $1^{-1-}$ monolayers were characterized by the presence of many inter-endothelial gaps (Fig. 1, c and f). L-NNA treatment partially restored the accumulation of $\beta$-catenin at AJs and resealed the gaps in $\mathrm{Cav}_{-} \mathrm{1}^{-/-}$monolayers (Fig. 1, c and e). Although AJs remained somewhat fragmented, they appeared to assemble as bands connecting adjacent cells. Interestingly, the PI3K p110 $\alpha$ isoform, which acts upstream of the Akt-1-eNOS signaling node, was shown to negatively regulate the integrity of AJs during inflammation by inducing the association of VE-cadherin with Pyk2 (Cain et al., 2010). It is likely therefore that Cav-1 deficiency is also accompanied by PI3K activation, and the destabilization of VE-cadherin adhesion seen in the $\mathrm{Cav}-\mathrm{I}^{-1-}$ monolayers might result from independent parallel signaling events. Nevertheless, our data suggest that Cav-1 modulates permeability of endothelial barrier, in part, through its negative regulation of eNOS activity.

To address mechanisms of eNOS modulation of AJ integrity, we determined the effects of NO on modification of AJ proteins. NO can lead to S-nitrosylation of cysteine, the covalent attachment of a NO group to the thiol side chain (Lima et al., 2010), and thus influence protein function. S-nitrosylation of $\beta$-catenin was shown to facilitate destabilization of AJs in response to VEGF signaling (Thibeault et al., 2010). Therefore, we determined S-nitrosothiol (SNO) content of $\beta$ - and p120-catenins and of p190RhoGAP-A (referred to as p190A), a binding partner of p120-catenin (Wildenberg et al., 2006). We reasoned that the apparent organization of actin cytoskeleton into stress fibers in $\mathrm{Cav}-1^{-1-}$ MLVECs (Fig. $1 \mathrm{c}$ ) might result from insufficient control of RhoA activity. p190A, a GTPase-activating protein (GAP), facilitates RhoA-GTP hydrolysis (Tatsis et al., 1998) and is a major regulator of RhoA activity at the level of AJs (Mammoto et al., 2007). SNO content, determined by the biotinswitch assay (Jaffrey and Snyder, 2001), of AJ proteins was indistinguishable between $\mathrm{Cav}-\mathrm{I}^{-1-}$ and Wt endothelia, although in a control experiment we could detect SNO of $\beta$-catenin in VEGFstimulated endothelial cells (Fig. 2 a). This finding raises the possibility that eNOS-redox signaling regulates integrity of AJs by other means.

When NO is accompanied by $\mathrm{O}_{2}^{\bullet-}$ generation, it forms peroxynitrite. The diffusion-controlled reaction of NO with $\mathrm{O}_{2}{ }^{\bullet-}$ is a likely source of peroxynitrite in cells and in vivo (Beckman et al., 1990; Jourd'heuil et al., 2001). The resulting peroxynitrite rapidly decomposes in the presence of ubiquitous $\mathrm{CO}_{2}$ to produce nitrate $\left(\mathrm{NO}_{3}{ }^{-}\right)$as a stable end product as well as carbonate $\left(\mathrm{CO}_{3}^{\bullet-}\right)$ and nitrogen dioxide $\left({ }^{\bullet} \mathrm{NO}_{2}\right)$ radicals (Bonini et al., 1999; Augusto et al., 2002), whose concerted action redirects peroxynitrite reactivity toward nitration of protein tyrosine residues (Santos et al., 2000). A direct measurement of peroxynitrite in cells is precluded by the extremely short lifetime of peroxynitrite at physiological $\mathrm{pH}$ and by the presence of metals, reductants, and $\mathrm{CO}_{2}$. Because peroxynitrite formation depends on both $\mathrm{O}_{2}{ }^{\bullet-}$ and $\mathrm{NO}$ and produces $\mathrm{NO}_{3}{ }^{-}$as the only stable product after oxidant decomposition, the use of superoxide scavengers followed by measurement of nitrite $\left(\mathrm{NO}_{2}{ }^{-}\right)$accumulation provides an assessment of peroxynitrite formation (Bonini et al., 2002). Agents such as polyethylene glycol-superoxide dismutase (PEG-SOD) and 4-hydroxy-2,2,6,6-tetramethylpiperidinyloxy (TEMPOL) in adequate concentrations outcompete $\mathrm{NO}$ for $\mathrm{O}_{2}^{\bullet-}$, thus favoring $\mathrm{NO}$ autoxidation and $\mathrm{NO}_{2}{ }^{-}$accumulation (Hoffman et al., 2003). Here we used TEMPOL/SOD-dependent $\mathrm{NO}_{2}{ }^{-}$accumulation to assess peroxynitrite formation. Both scavengers had marginal effects on accumulation of nitrite resulting from basal NO production in Wt cells (Fig. 2 b); in contrast, accumulation of nitrite was significantly higher in $\mathrm{Cav}-1^{-1-}$ cells (Fig. 2 b). Consistent with this observation, Cav-1 deficiency was accompanied by a twofold increase in $\mathrm{O}_{2}^{\bullet-}$ generation (Fig. 2 c), as measured by formation of 2-hydroxyethidium $(\mathrm{EOH})$, a product of dihydroethidium (DHE) oxidation. Furthermore, adding tetrahydrobiopterin $\left(\mathrm{BH}_{4}\right)$ to these cells, but not L-arginine, restored $\mathrm{O}_{2}{ }^{\bullet-}$ generation to the level seen in $\mathrm{Wt}$ cells (Fig. 2 c), which suggests that $\mathrm{BH}_{4}$ deprivation-mediated uncoupling eNOS from NO generation is the primary mechanism of $\mathrm{O}_{2}{ }^{\bullet-}$ generation in the $\mathrm{Cav}-\mathrm{I}^{-1-}$ endothelial cells. We thus concluded that up-regulation of eNOS activity in $\mathrm{Cav}-1^{-1-}$ endothelium results in an augmented generation of both NO and $\mathrm{O}_{2}^{\bullet-}$ and thereby the formation of peroxynitrite.

We next determined the nitration of AJ proteins by probing immunoprecipitated proteins with anti-nitrotyrosine antibody (3-N). We failed to detect any change in nitration of either $\beta$ - or p120-catenins in Cav-1 ${ }^{-/-}$endothelial monolayers (Fig. 2 d); however, nitration of p190A was significantly increased (Fig. 2 e). 
Figure 2. Peroxynitrite generation in $\mathrm{Cav}^{-1} \mathrm{1}^{-/-}$endothelium and nitration of p190A. (a) S-nitrosylation of $\beta$ - and p120-catenins, and p190A. Proteins were co-immunoprecipitated with specific Abs, and precipitates were probed with HRP-avidin; results of two independent experiments are shown; $n=4$. Note that the $\beta$-catenin band is indicated by an arrow. SNO of $\beta$-catenin in VEGF-treated cells is a positive control. Molecular mass standards are indicated next to the gel blots in kilodaltons. (b) The bar plot shows nitrite accumulation in the presence of SOD and TEM$\mathrm{POL}$; mean $\pm \mathrm{SEM}$ (error bars); ${ }^{*}, \mathrm{P}<0.05$ as compared with $W_{t}$ control; $n=4$. (c) Bar plot shows the fluorescence emission of $\mathrm{EOH}$ at $580 \mathrm{~nm}$; mean \pm SEM (error bars); ${ }^{*}, \mathrm{P}<0.05$ as compared with $W_{t}$ control; $n=4$. (d) $\beta$ - and p120-catenins and (e) p190A were co-immunoprecipitated with specific Abs, and precipitates were probed for nitrotyrosine (3-N). Results of two independent experiments are shown; $n=4$. (e) Cav-1 deletion induced the nitration of p190A, which was reduced by TEMPOL treatment and in cells isolated from lungs of Cav-1/eNOS double knockout mice (DKO). (e, right) Bar plot; fold increase in p190A nitration normalized to p190A loading; mean \pm SEM (error bars); ${ }^{*}, P<0.05$ as compared with $\mathrm{Wt} ; n=4$.
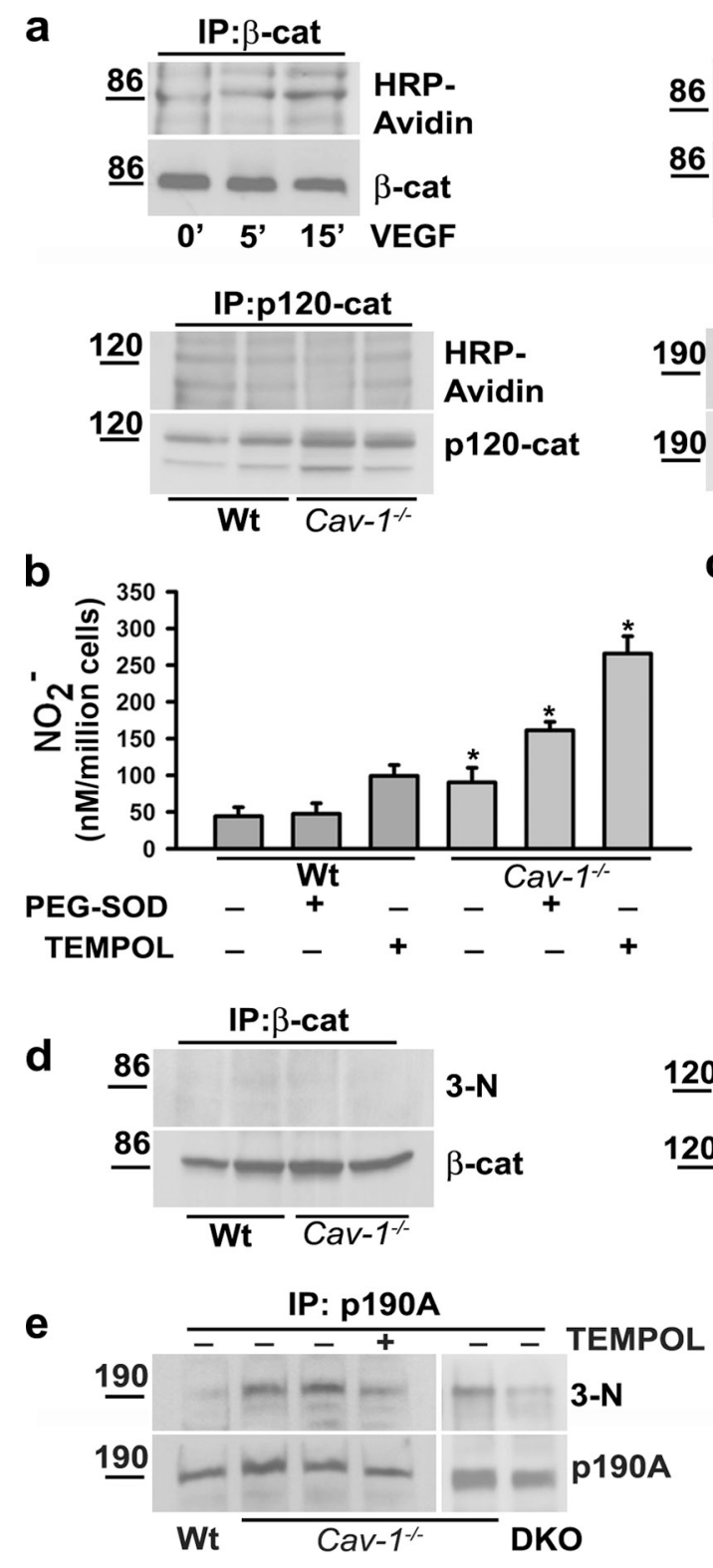
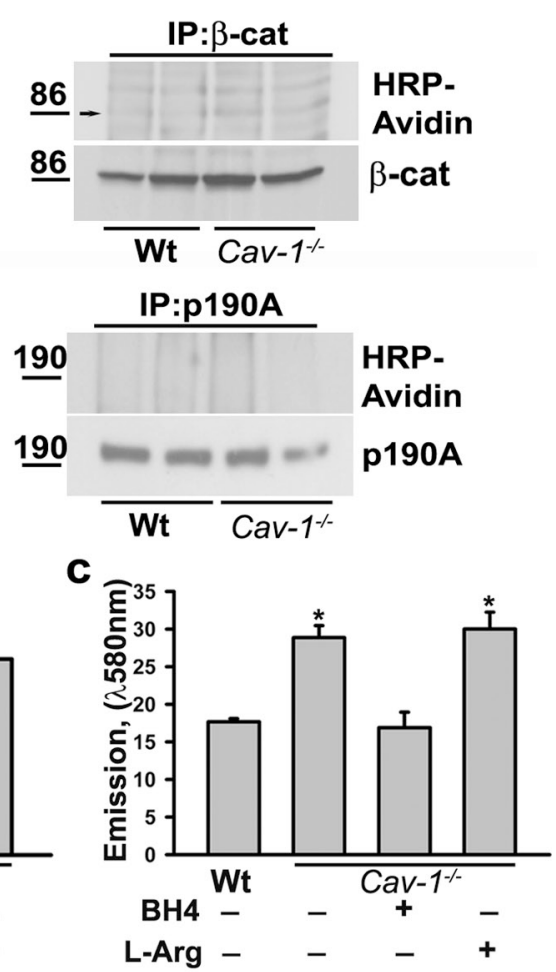

IP: p120-cat
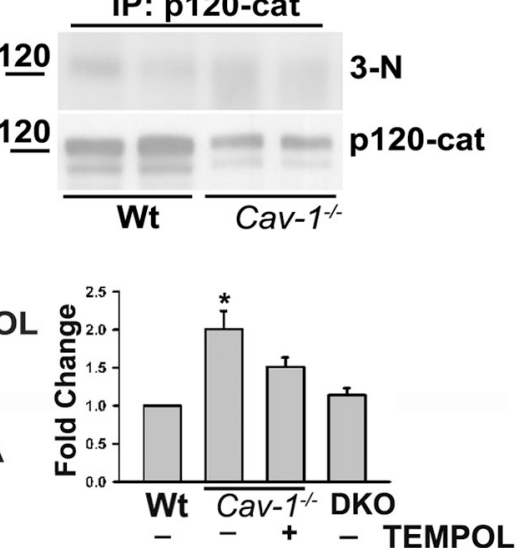

We also found marked reduction in p190A nitration in $\mathrm{Cav}^{-1^{-1-}}$ endothelial cells pretreated with TEMPOL and in MLVECs isolated from lung vessels of Cav-1/eNOS double knockout mice (Fig. 2 e). Nitration of p190A also appeared to be reversible because scavenging of $\mathrm{O}_{2}{ }^{\bullet-}$ significantly reduced the nitrated protein levels, although the p190A expression level itself remained unchanged (Fig. 2 e). We speculate that nitration, which in some cases targets proteins for proteolytic degradation (Grune et al., 1998), does not regulate the metabolism and turnover of p190A. The dogma of irreversible nitration of proteins is under debate, and it is also now increasingly evident that the action of peroxynitrite might be specific (Aulak et al., 2004; Görg et al., 2007).

Nitration compromises protein function by altering tyrosine phosphorylation (Gow et al., 1996). The ability of p190A to hydrolyze RhoA is regulated by c-Src and FAK phosphorylation of p190A (Chang et al., 1995; Holinstat et al., 2006). Therefore, we tested whether nitration alters tyrosine phosphorylation of p190A, which could thereby inhibit its GAP activity. We found a marked decrease in p190A phosphorylation in $\mathrm{Cav}_{-1} \mathrm{I}^{-1-}$ MLVECs (Fig. 3 a). We next addressed whether $\mathrm{Y}^{1105}$, the phosphorylation site critical for p190A activity (Roof et al., 1998), might be targeted for nitration. Mutation of $Y^{1105}$, but not $Y^{1087}$, to phenylalanine $(\mathrm{Y} \rightarrow \mathrm{F})$ prevented the chemically induced nitration of p190A by 3-morpholinosydnonimine (SIN-1; Fig. 3 b). SIN-1 also induced nitration of endogenous and transiently expressed Wt p190A but not of p190RhoGAP-B (Fig. 3 b).

Down-regulation of p190A activity results in RhoA activation (Vincent and Settleman, 1999), which may increase junctional permeability (Holinstat et al., 2006). We thus determined whether nitration of $\mathrm{p} 190 \mathrm{~A}$ results in RhoA activation in the $\mathrm{Cav}_{-1} \mathrm{I}^{-1-}$ endothelium. For this, we assessed RhoA activity using the FRET-based RhoA biosensor (Pertz et al., 2006). Ratio images revealed a twofold increase in RhoA activity in $\mathrm{Cav}_{-1} \mathrm{I}^{-1-}$ monolayers compared with Wt (Fig. 3, c and d). We detected uniform RhoA activity from the edge of the cell inwards with 


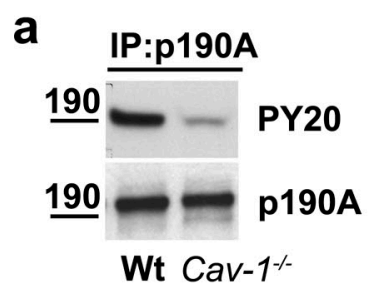

b IP: $\underline{\operatorname{lgG}} \underline{190 \mathrm{~A}} \frac{\mathrm{HA}}{190 \mathrm{~A} 10871105}$
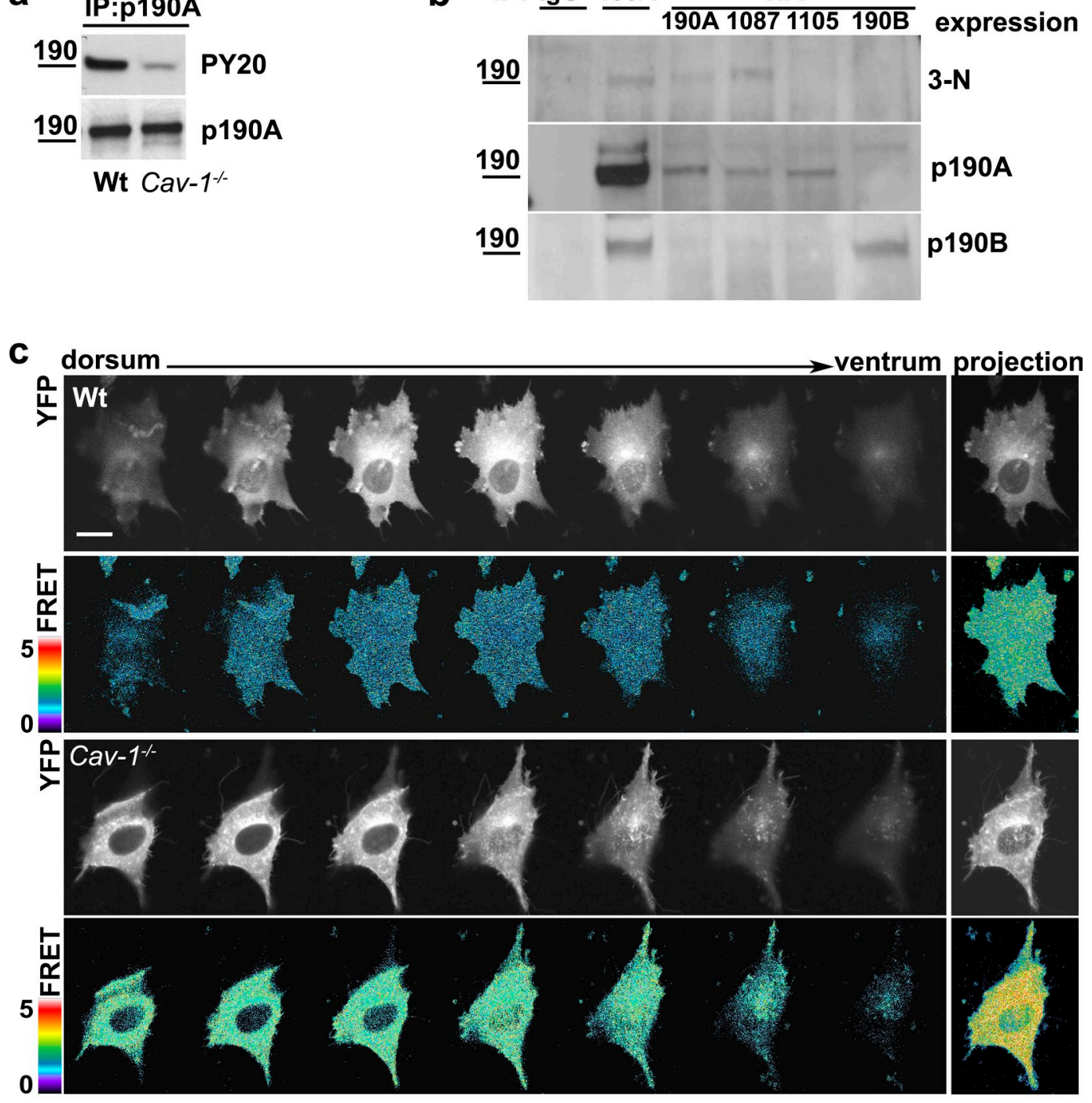

e
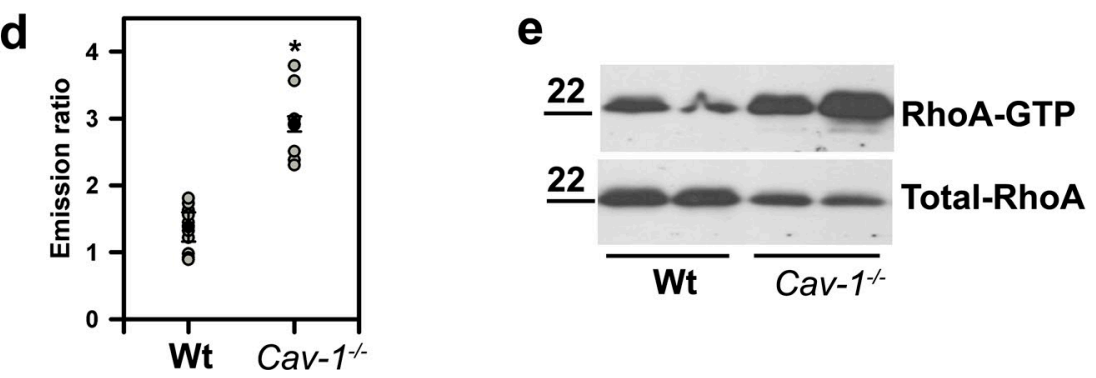

Figure 3. Nitration of p190A induces RhoA activation in endothelial cells. (a) p190A was co-immunoprecipitated and precipitates were probed for phosphotyrosine (PY20) and p190A; $n=3$. Molecular mass standards are indicated next to the gel blots in kilodaltons. (b) Human microvascular endothelial cells (dermal) overexpressing HA-tagged p190A, p190B, or p190A mutants Y1105F and Y1087F were treated with SIN-1. Nitration of endogenous p190A and exogenously expressed proteins was determined with 3-N antibody. Exogenous proteins were co-immunoprecipitated with anti-HA antibody; $n=3$. (c) Live imaging of a genetically encoded FRET-based RhoA biosensor. Representative YFP and FRET/CFP ratio confocal images. Pixel intensities of ratio images were scaled from 0 to 5 and color-coded as indicated on the left. Bar, $10 \mu \mathrm{m}$. (d) FRET/CFP emission ratio; mean and SEM are as in Fig. 1 e; $n=13 ;{ }^{*}, P<0.01$. (e) RhoA-GTP was pulled down with Rhotekin-RBD beads. Resultant precipitates and $5 \%$ of cell extracts were probed for RhoA; results of two independent experiments are shown; $n=4$. Molecular mass standards are indicated next to the gel blots in kilodaltons.

very little and infrequent accumulation at cell edges and along extensions (Fig. 3 c), which is consistent with the distribution of active RhoA in other nonmigrating cells (Pertz et al., 2006). Notably, we observed a fourfold increase in RhoA activity by the pulldown of RhoA-GTP with Rhotekin beads (Fig. 3 e).
To demonstrate the causal link between RhoA activity and destabilization of AJs, we attempted to restore integrity of AJs in $C a v-1^{-l-}$ MLVECs by inhibiting RhoA. Treatment of Cav-1 $1^{-/-}$ endothelium with the Rho inhibitor C3-transferase significantly reduced phosphorylation of myosin light chain (MLC), a 
Figure 4. Restoration of normal paracellular permeability in $\mathrm{Cav}^{-1^{-/-}}$endothelial monolayers and vessels by inhibition of either RhoA or eNOS. (a) Immunofluorescent staining of MLVECs isolated from $\mathrm{Cav}_{-1} 1^{-/-}$and $\mathrm{Cav}-1 /$ eNOS double knockout (DKO) mice for $\beta$-catenin (green), F-actin (red), and nuclei (blue). Cav- ${ }^{-1-}$ cells were treated with Rho inhibitor C3 transferase and AP-CSD peptide. Bar, $10 \mu \mathrm{m}$. (b) $\beta$-catenin accumulation at Als as in Fig. $1 \mathrm{e}$ ${ }^{*}, \mathrm{P}<0.01$ as compared with $\mathrm{Wt}$ control; ${ }^{*}, \mathrm{P}<0.01$ as compared with $\mathrm{Cav}_{-1}^{-1-} ; n=10$. (c) Endothelial permeability to EBA; mean and SEM are as in Fig. $1 \mathrm{e}$; ${ }^{*}, \mathrm{P}<0.01$ as compared with $\mathrm{Wt}$ control; ${ }^{*}, \mathrm{P}<0.05$ as compared with $\mathrm{Cav}_{-1}{ }^{-1-} ; n=4$. (d) Lung weight changes after a step increase in transvascular oncotic pressure gradient. Recordings were smoothed by averaging successive groups of five points. Lungs isolated from $\mathrm{Wt}$ and Cav- $1^{-1-}$ mice were perfused with $0 \%$ BSA for 10 min with $10 \%$ BSA for $30 \mathrm{~min}$, and with $0 \%$ BSA for $10 \mathrm{~min}$; an additional $\mathrm{Cav}_{-1}{ }^{-1-}$ group received AP-CSD peptide starting at 10 min of BSA profusion. AP-CSD peptide reversed lung weight loss during high albumin perfusion in $\mathrm{Cav}_{-1} 7^{-1-}$ lungs and largely restored the transvascular fluid filtration rate between 40 and $50 \mathrm{~min}$. (e) The filtration rate was calculated from the initial slope of slow exponential component of lung weight gain; mean and SEM are as in Fig. 1 e; ${ }^{*}, P<0.05$ as compared with Wt control; $n=5-9$. a Cav-1\%
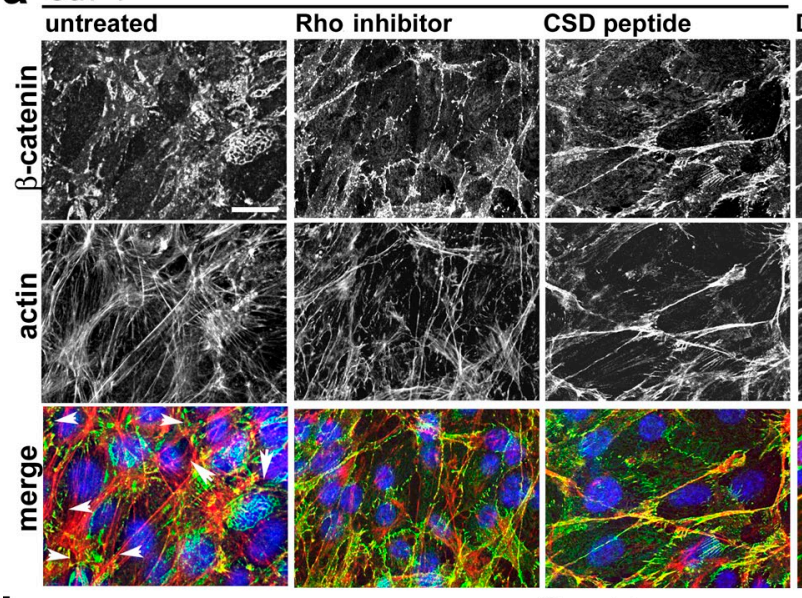

DKO

b.
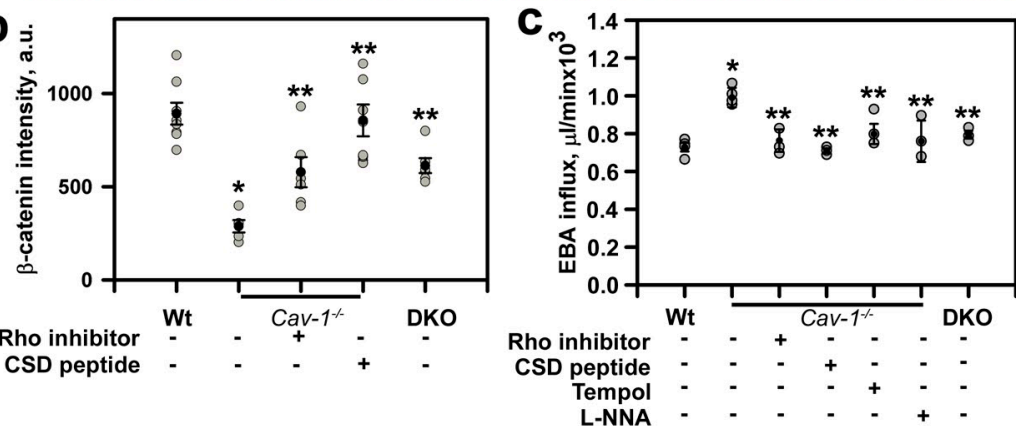

d

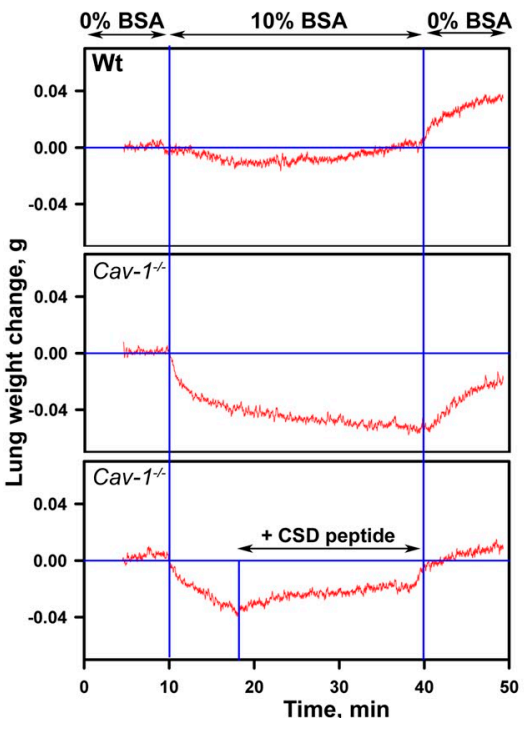

\section{e}

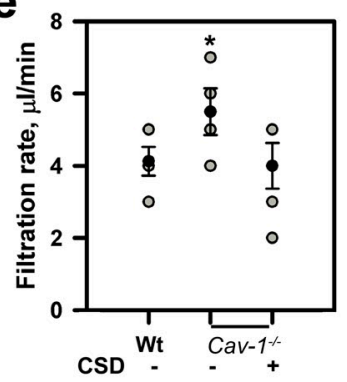

downstream effector of RhoA/ROCK, in $\mathrm{Cav}^{-1^{-1-}}$ cells (Fig. S2). It also rescued $\beta$-catenin accumulation at $\mathrm{AJ}$ s and restored permeability of $\mathrm{Cav}-1^{-1-}$ monolayers to the Evans blue albumin (EBA) tracer (Fig. 4, a-c). Treatment of $\mathrm{Cav}^{-1^{-1-}}$ endothelium with Cav-1 scaffold domain (CSD)-antennapedia (AP) fusion peptide, which binds to and suppresses eNOS catalytic activity (Bucci et al., 2000), superoxide scavenger TEMPOL, and L-NNA as well as Cav-1/eNOS deficiency (DKO) also restored the integrity of AJs and the permeability of $\mathrm{Cav}^{-1^{-1-}}$ monolayers (Fig. 4, a-c). We concluded therefore that nitration of $\mathrm{p} 190 \mathrm{~A}$ provides a reversible switch mechanism regulating RhoA activity and thereby endothelial barrier integrity.
To address the role of Cav-1-eNOS interaction in the mechanism of increased paracellular permeability in vivo, we recorded fluid shift in isolated-perfused murine lungs by the gravimetric method in response to a standard perturbation of the trans-endothelial oncotic pressure gradient $\left(\pi_{c}-\pi_{i}\right.$; Fig. 4 d). Elevating perfusate albumin from 0 to $10 \mathrm{~g} / 100 \mathrm{ml}$ caused significantly greater dehydration of lungs of $\mathrm{Cav}-\mathrm{I}^{-/-}$mice than in Wt control (Fig. 4 d), which indicates much faster equilibration of fluid across the endothelium devoid of Cav-1 expression. The lung weight gain (during the 40-50th min of the experiment) was fit to a double exponential function characterizing the fast and slow filtration processes (Table S1). The filtration rate calculated 

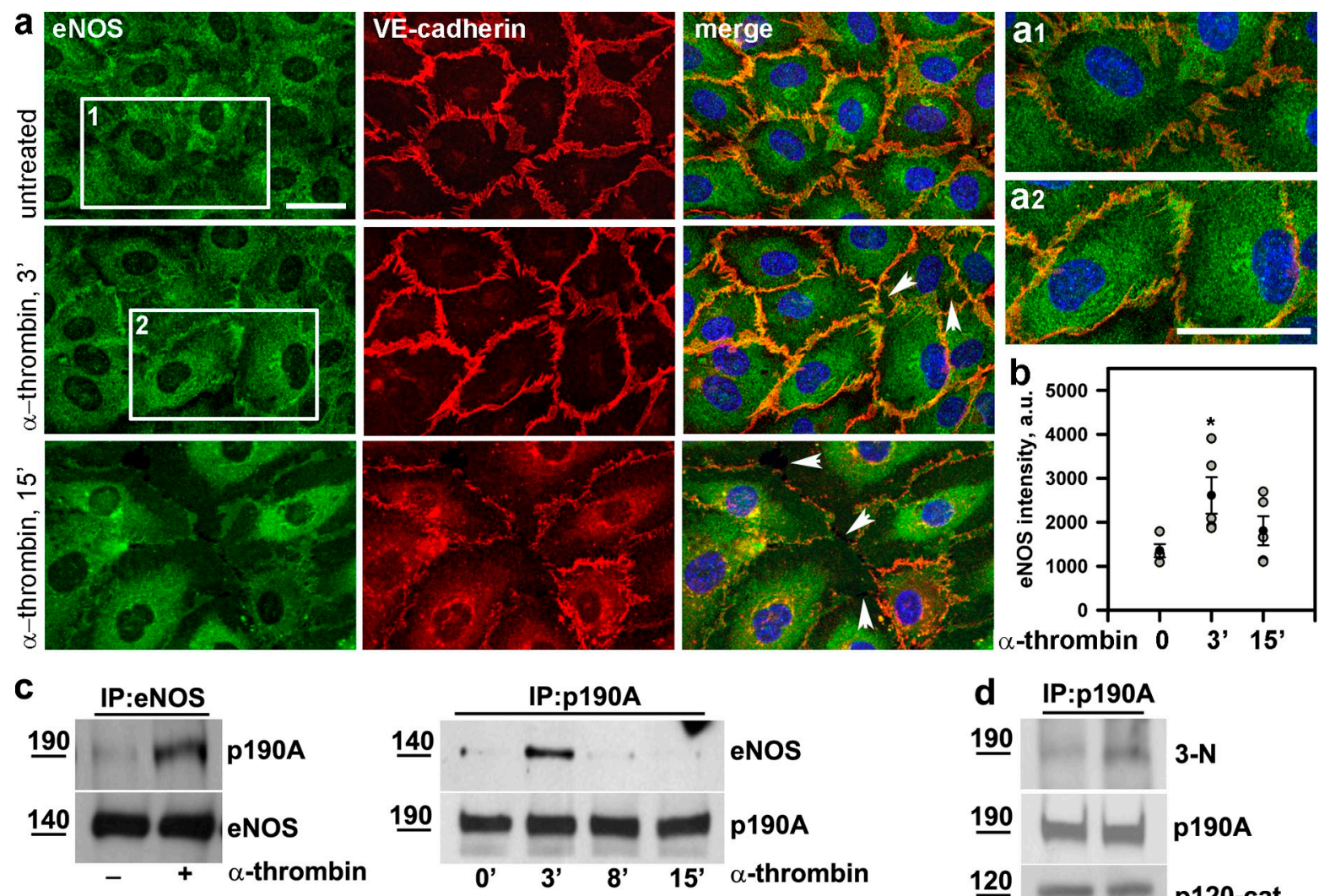

\section{e}

\begin{abstract}
Restricted paracellular transport
\end{abstract}

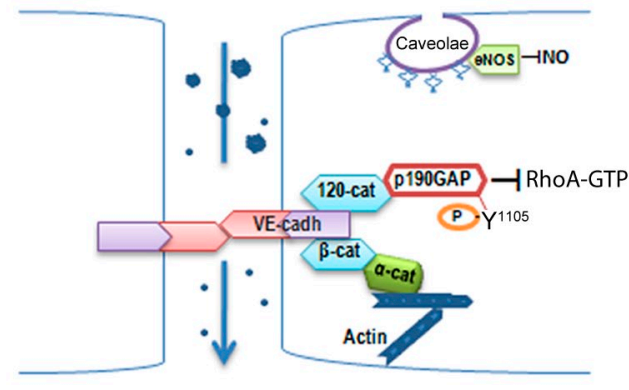

\section{Increased para-} cellular transport

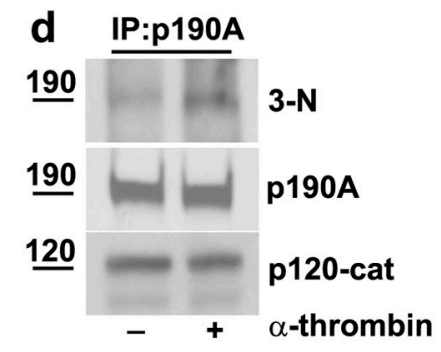

Figure 5. eNOS-dependent NO-redox signaling disrupts AJ integrity. (a) Immunofluorescent staining of HPAECs for eNOS (green) and $\beta$-cat (red). DAPI (blue) is shown before and after stimulation with $50 \mathrm{nM} \alpha$-thrombin. al and a2 are enlarged views of boxed regions; inter-endothelial gaps are indicated by arrowheads. Bars, $10 \mu \mathrm{m}$. (b) eNOS accumulation at Ass was measured as in Fig. 1 e with some modification (see Materials and methods); *, $\mathrm{P}<0.05$ as compared with $W_{t}$ control; $n=6$. $\alpha$-Thrombin induced transient accumulation of eNOS at Als. (c and d) $\alpha$-Thrombin induced transient interaction between eNOS and p190A and nitration of p190A. eNOS and p190A were co-immunoprecipitated with specific Abs from HPAECs stimulated with $50 \mathrm{nM} \alpha$-thrombin. Precipitates were probed for p190A, eNOS, 3-N, and p120-catenin. Molecular mass standards are indicated next to the gel blots in kilodaltons. (e) Model showing that Cav-1-mediated recruitment of eNOS into caveolar domain allows formation of stable endothelial VE-cadherin adhesions, which restricts the permeability of the paracellular route to plasma proteins. Deficiency in Cav-1 or release of eNOS from caveolae results in activation of eNOS, translocation of eNOS to $\mathrm{Ass}$, and transient interaction with p190A. Peroxynitrite, a product of $\mathrm{NO}$ and $\mathrm{O}_{2}{ }^{\bullet-}$, inhibits p190A activity by nitrating $Y^{1105}$. Activation of RhoA leads to reorganization of the actin cytoskeleton, actomyosin contractility, destabilization of AJs, and increased vascular permeability via the paracellular pathway.

from the initial slope of the slow exponential component was significantly greater in $C a v-1^{-1-}(5.5 \pm 0.6 \mu \mathrm{l} / \mathrm{min} ; n=5)$ than in Wt $(4.1 \pm 0.3 \mu \mathrm{l} / \mathrm{min} ; n=9)$ lungs (Fig. 4 e). Perfusion with AP-CSD peptide that reanneals open IEJs (Fig. 4 a) restored transvascular fluid filtration in $\mathrm{Cav}_{-} \mathrm{1}^{-/-}$lungs to the Wt values (Fig. 4, d and e). We infer therefore that Cav-1 regulates the permeability of the paracellular or AJ pathways mainly by functioning to restrain the eNOS activity.
The NO redox endothelial permeability-increasing mechanism described in this paper may contribute to deregulation of tissue fluid homeostasis during inflammation, which is known to be accompanied by loss of p190A activity and activation of RhoA (Mammoto et al., 2007). Therefore, we determined whether stimulation of endothelial cell monolayers with a proinflammatory mediator such as the serine protease thrombin induces p190A nitration. Thrombin proteolytically cleaves and 
activates the protease-activated receptor PAR-1 on the endothelial surface, leading to increased intracellular calcium concentration and activation of eNOS (Motley et al., 2007). Challenge of human pulmonary artery endothelial cells (HPAECs) with $\alpha$-thrombin resulted in translocation of eNOS to AJs and a transient interaction between eNOS and p190A and nitration of p190A (Fig. 5, a-d). Nitrated p190A also remained bound to p120catenin (Fig. 5 d). Thus, we suggest that the signaling mechanism responsible for increased vascular permeability described in this study may be important in inflammatory diseases, and hence we propose it represents a novel anti-inflammatory therapeutic target.

In conclusion, our study demonstrates that paracellular permeability of the endothelium is finely regulated by constitutive Cav-1-dependent inhibition of eNOS activity (Fig. 5 e). Deficiency in Cav-1 or activation of eNOS in conjunction with $\mathrm{O}_{2}{ }^{\mathbf{-}}$ production results in nitration of p190A and the concomitant activation of RhoA, which induces AJ destabilization and increased endothelial permeability. Because of the causal relationship of eNOS-specific signaling to the impairment of p190A activity, this mechanism induces RhoA activation in endothelial cells. In fibroblasts, however, Cav-1 depletion induces Src-dependent activation of p190A, resulting in loss of cell polarity and impaired wound healing (Grande-García et al., 2007). In contrast, in endothelial cells, Cav-1 knockdown increases directional migration (Gonzalez et al., 2004); thus, our findings help to inform the unique role of Cav-1 expression on p190A activity in endothelial cells and how Cav-1 regulates the permeability of the endothelial junctional barrier.

\section{Materials and methods}

\section{Antibodies and reagents}

We used anti-HA (clone 16B12; Covance), anti-phosphotyrosine (PY20), and PECAM-1 (BD); anti-VE-cadherin, anti- $\beta$-actin, anti- $\beta$, and anti-p120 catenins; anti-RhoA, anti-eNOS, and anti-Cav-1 (Santa Cruz Biotechnology, Inc.); anti-p190RhoGAP (Sigma-Aldrich); anti-nitrotyrosine, antiAkt, and anti-MLC 2; and phospho-eNOS-Ser ${ }^{1177}$, phospho-Akt-Ser ${ }^{473}$, and phospho-MLC2-Thr ${ }^{18} / \mathrm{Ser}^{19}$ (Cell Signaling Technology). Secondary Abs were HRP-conjugated donkey anti-mouse, anti-rabbit, and anti-goat (Jackson ImmunoResearch Laboratories, Inc.); TRITC-, FITC-, and Cy-5-conjugated donkey anti-mouse, anti-goat, and anti-rabbit (Jackson ImmunoResearch Laboratories, Inc.), Alexa Fluor 532 phalloidin, and DAPI (Sigma-Aldrich).

We used protein A/G beads (Santa Cruz Biotechnology, Inc.), DHE, and Dynabeads M-450 (Invitrogen). We also used a Rho activation assay kit and Rho inhibitor C3 transferase (Cytoskeleton), SIN-1 (EMD), NPA, L-NNA, and 1400W (Cayman Chemical), PEG-SOD, TEMPOL, (6R)-5, 6,7,8tetrahydrobiopterin dihydrochloride (BH4), l-arginine, sodium iodide, and sodium nitrite (Sigma-Aldrich), as well as AP-CSD peptide (EMD).

\section{Expression constructs, primers, and RT-PCR}

HA-tagged rat P190A and P190B, Y1105F, and Y1087F mutants of p190A were gifts from S.J. Parsons (University of Virginia, Charlottesville, VA); the RhoA biosensor was from K. Hahn (University of North Carolina at Chapel Hill, Chapel Hill, NC). The mRNA was assessed by quantitative real-time PCR (Rajasingh et al., 2008). Primer and probe sequences were as follows: Cav-1 forward, 5'-CAGCATGTCTGGGGGTAAAT-3', and reverse, 5'-TGCTTCTCATTCACCTCGTCT-3'; Cav-2 forward, 5'-TGTTTCTAGCCATCCCCTTG-3', and reverse, 5'-ACCATGAGGCAGGTCTTCAC-3'; eNOS forward, 5'-TCTGCGGCGATGTCACTATG-3', and reverse 5'-CATGCCGCCCTCTGTTG-3'; VE-cadherin forward, 5'-GTGGATGAGCCCCCTGTCT-3'; and reverse, 5'-CAGCGGTTCTTCTGGTTTCT-3'; and VW-F forward, 5'-GCTTCCAACTGAACTGTGAGACCT-3'; and reverse, 5'-GGCTGTGATGTCTTTGCAATCAG-3'. The relative mRNA expression was normalized to the 18S gene (Applied Biosystems).

\section{Cell culture, treatments, and transfection}

$\mathrm{Cav}^{-1^{-/-}}$and matching control mice of $\mathrm{C} 57 \mathrm{bl} / 6$ background were obtained from The Jackson Laboratory (JAX mice and services). Cav- 1 /eNOS double knockout was produced as described previously (Zhao et al., 2009). MLVECs were isolated as described previously (Garrean et al., 2006), with some modification. In brief, 3-4-wk-old mice were anesthetized by using isoflurane $(2.5 \%$ in room air) according to the protocol approved by the University of Illinois Animal Care Committee. Depth of anesthesia was ascertained by loss of pain reflex to a vigorous paw pinch. After exsanguination, the lung was perfused with sterile HBSS supplemented with antibiotics. Lung was removed, minced, and digested with collagenase A $\left(1.0 \mathrm{mg} / \mathrm{ml}\right.$ in HBSS ) for $60 \mathrm{~min}$ at $37^{\circ} \mathrm{C}$ on shaker. The released cells were centrifuged at $200 \mathrm{~g}$ for $10 \mathrm{~min}$. The pellet was suspended in $10 \mathrm{ml}$ of suspension buffer $\left(\mathrm{Ca}^{2+}\right.$ - and $\mathrm{Mg}^{2+}$-free PBS containing $0.5 \mathrm{~g} / 100 \mathrm{ml}$ bovine serum albumin, $2 \mathrm{mM}$ EDTA, and $4.5 \mathrm{mg} / \mathrm{ml}$ D-glucose), and filtered through a 200- $\mu \mathrm{m}$ mesh sterile filter. The cell suspension was incubated with $10 \mu \mathrm{gg}$ of anti-mouse PECAM- 1 antibody on ice for $1 \mathrm{~h}$, centrifuged to remove unbound antibody, and washed once with suspension buffer. The cells were incubated with Dynabeads M-450 (Sheep anti-rat lgG) for $60 \mathrm{~min}$ at $4^{\circ} \mathrm{C}$. The cells attached to Dynabeads were trapped in a magnetic column to separate a subpopulation of PECAM-1-positive cells, washed, and resuspended in endothelial growth medium EGM-2 MV medium (Lonza), supplemented with 10\% FBS (Invitrogen), and seeded in Matrigel-coated culture dishes (BD).

MLVECs and human lung microvascular endothelial cells (HMVEC-Ls; Lonza) were grown in EGM-2 MV medium (Lonza) supplemented with $15 \%$ FBS (Invitrogen). HPAECs (Lonza) were grown in EGM-2 medium (Lonza) supplemented with 15\% FBS (Invitrogen). Endothelial cells were used at passages 2-6. Human microvascular endothelial cell (HMECs; dermal; Lonza) were grown in MCDB 131 medium (Invitrogen) supplemented with $10 \% \mathrm{FBS}, 0.003 \mathrm{\mu g} / \mathrm{ml}$ h-EGF, $0.001 \mathrm{mg} / \mathrm{ml}$ hydrocortisone, and l-glutamine.

For measurement of basal NO generation, cells were incubated in L-arginine-free EBM media (Lonza) for $2 \mathrm{~h}$. Cells were treated with

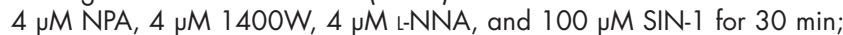
and with $150 \mathrm{U} / \mathrm{ml}$ PEG-SOD, $100 \mu \mathrm{M}$ TEMPOL, $2 \mu \mathrm{g} / \mathrm{ml}$ Rho inhibitor C3 transferase, and $6 \mu \mathrm{M}$ AP-CSD peptide for $2 \mathrm{~h}$. $70-80 \%$ confluent monolayers were transfected using FuGENE HD (Rhoche) and Lipofectamine 2000 (Invitrogen) transfection reagents in accordance with the manufacturer's instructions.

\section{Co-immunoprecipitation and Western blotting}

Cells were lysed in modified RIPA buffer $(50 \mathrm{mM}$ Tris-HCl, pH 7.5, $150 \mathrm{mM}$ $\mathrm{NaCl}, 1 \mathrm{mM}$ EDTA, 1\% Triton X-100, 0.5\% sodium deoxycholate, $0.1 \%$ SDS, $1 \mathrm{mM} \mathrm{Na}_{3} \mathrm{VO}_{4}, 10 \mu \mathrm{g} / \mathrm{ml}$ leupeptin, $10 \mu \mathrm{g} / \mathrm{ml}$ aprotinin, and $0.1 \mathrm{mM}$ PMSF). For co-immunoprecipitation experiments, $350 \mu \mathrm{g}$ of total protein was incubated with $15 \mu \mathrm{g}$ of antibody at $4^{\circ} \mathrm{C}$, and precipitates were collected with protein $A / G$ agarose beads. Densitometry of blots was performed using ImageJ software (National Institutes of Health).

\section{RhoA-GTP pull-down assay}

RhoA activity was determined by pull-down assays using GST-Rhotekin beads (Knezevic et al., 2007). Cells were lysed in $50 \mathrm{mM}$ Tris- $\mathrm{HCl}, \mathrm{pH}$ 7.5, $10 \mathrm{mM} \mathrm{MgCl}, 0.5 \mathrm{M} \mathrm{NaCl}, 1 \%$ Triton X-100, $0.5 \%$ sodium deoxycholate, $0.1 \%$ SDS, $10 \mu \mathrm{g} / \mathrm{ml}$ leupeptin, $10 \mu \mathrm{g} / \mathrm{ml}$ aprotinin, and $0.1 \mathrm{mM}$ PMSF. Cell lysates were incubated with GST-RBD beads at $4{ }^{\circ} \mathrm{C}$ and bound proteins were analyzed by Western blotting. $5 \%$ of cell lysates were used to detect total RhoA.

\section{NO measurement}

NO formation was measured using porphyrinic NO electrodes (Brovkovych et al., 1999). Electrodes were calibrated using a stock solution of NOsaturated water. The $\mathrm{NO}$ electrode was placed onto the cell surface and two additional electrodes were added into the solution to generate a $650-\mathrm{mV}$ potential. The system was coupled to a FASI femtostat and a personal computer with electrochemical software (Gamry Instruments). The electrode current, which is proportional to NO concentration, was measured as a function of time.

\section{Nitrite measurement}

Nitrite accumulation in cell culture media was assessed by a chemiluminescence assay (Bonini et al., 2002) using an NO Analyzer (NOA 280i; GE Healthcare). Authentic $\mathrm{NaNO}_{2}$ solutions of known concentrations were used as standards. All measurements were performed relative to cellfree controls. 


\section{Measurement of intracellular superoxide}

Cells plated in a 96-well plate were left untreated or incubated with $50 \mu \mathrm{M}$ $\mathrm{BH}_{4}$ or $500 \mu \mathrm{M}$ l-arginine for $30 \mathrm{~min}$, then treated with $50 \mu \mathrm{M} \mathrm{DHE}$ for $1 \mathrm{~h}$. Emission of EOH, a product of DHE oxidation, at $\lambda=580 \mathrm{~nm}$, was measured using a SpectraMax M5e Multi-Mode Microplate Reader (Molecular Devices).

\section{SNO measurement}

SNO content of junctional proteins was detected by biotin-switch method using the S-nitrosylated Detection Assay kit (Cayman Chemical) according to the manufacturer's instructions. The biotin-labeled proteins were precipitated with ice-cold acetone, and $350 \mathrm{\mu g}$ of total protein was used for co-immunoprecipitation with specific Abs. SNO content was detected with SNO detection reagent I on Western blots. The same blot was reprobed for protein of interest.

\section{Immunofluorescence staining and image analysis}

Cell were fixed with $4 \%$ paraformaldehyde, permeabilized with $0.2 \%$ Triton X-100, and stained as described previously (Komarova et al., 2002). Samples were mounted with ProLong-Gold antifade reagent (Invitrogen) Z-stack images were obtained using a confocal microscope (LSM 510 Meta; Carl Zeiss) equipped with a $63 x, 1.2$ NA water immersion objective lens and $\mathrm{Ar}$ ion and dual HeNe lasers, and driven by LSM software. 12-bit images were analyzed using MetaMorph software (Molecular Devices) and prepared for illustration in Photoshop (Adobe). Projection images were generated by collecting the maximum pixel intensity from each image of the $z$ stack and by projecting pixel intensity onto the single (projection) image. The relative accumulation of $\beta$-catenin (mean fluorescence intensity) at $\mathrm{AJs}$ and the area of gaps were measured on projected images. The 12-bit images were thresholded by subtracting intracellular background, and the mean fluorescence intensity at Als was measured. For measurement of eNOS accumulation at A $\mathrm{s}$, the corresponding VE-cadherin image was used to generate a binary mask within 0 (outside of $\mathrm{A} J \mathrm{~s}$ ) and 1 ( $\mathrm{A} / \mathrm{s}$ area) values after subtracting intracellular background, and the eNOS image was multiplied by a binary mask image for VE-cadherin. The mean fluorescence intensity of eNOS at AJs was then measured as described for $\beta$-catenin. Gap area was expressed as a percentage of the area outside of the cell.

\section{Live cell imaging and image processing}

Cells were imaged in phenol-free EBM media (Lonza) supplemented with $5 \% \mathrm{FBS}$ at $37^{\circ} \mathrm{C}$ maintained by the stage heater (Tempcontrol-37; Carl Zeiss). Z-stack images were obtained using a confocal microscope (LSM 510 Meta; Carl Zeiss) equipped with a 63x, 1.2 NA water immersion objective lens and $\mathrm{Ar}$ ion and dual $\mathrm{HeNe}$ lasers. For emission ratio imaging, we acquired 12-bit CFP $(\lambda=458 \mathrm{~nm}$; BP500/20), FRET $(\lambda=458 \mathrm{~nm}$; LP530), and YFP ( $\lambda=514 \mathrm{~nm}$; LP530) images. All images were processed and analyzed using MetaMorph software. The FRET image was used to generate a binary mask within $0-1$ values. To generate a ratio image reflecting RhoA activity, the FRET image was first multiplied by a binary mask image and then divided by the CFP image. The ratio images were rescaled to the lower value and a linear pseudocolor table was applied to generate the color-coded image map. The $z$ stack FRET/CFP emission ratio images were used to generate the projection image. The relative RhoA activity was expressed as mean pixel intensity.

\section{Endothelial barrier permeability measurement}

The permeability of MLVECs monolayer to EBA was determined as described previously (Patterson et al., 1992). Cells were grown to confluence on transwell inserts with a $0.4 \mu \mathrm{m}$ pore size. Upper (luminal) and lower (abluminal) chambers were filled with HBSS containing $0.5 \%$ BSA and $20 \mathrm{mM}$ Hepes. After a 30-min equilibration period, the luminal chamber was loaded with $0.057 \%$ EBA. Samples from the abluminal chamber were collected every $5 \mathrm{~min}$ for $1 \mathrm{~h}$. EBA concentration was calculated from the optical density measured at $620 \mathrm{~nm}$ with the aid of the SpectraMax Plus microplate spectrophotometer (Molecular Devices). The rate of EBA clearance from luminal chamber was determined by linear regression between 5 and $60 \mathrm{~min}$.

\section{Perfusion of mouse lungs and measurement of transvascular fluid filtration}

Murine lung preparations from WT and $\mathrm{Cav}_{-} \mathrm{T}^{-1-}$ male mice $(\mathrm{C} 57 \mathrm{bl} / 6$ strain) were performed according to an approved protocol of the University of Illinois at Chicago Animal Care Committee (Vogel et al., 2006). In brief, isolated lung preparations were perfused with RPMI medium at constant flow $(2 \mathrm{ml} / \mathrm{min})$, temperature $\left(37^{\circ} \mathrm{C}\right)$, and venous pressure $\left(4 \mathrm{~cm} \mathrm{H} \mathrm{H}_{2} \mathrm{O}\right.$ ).
The preparation was ventilated at a rate of 120 breaths per min, at constant peak inspiratory $\left(\sim 10 \mathrm{~cm} \mathrm{H}_{2} \mathrm{O}\right)$ and end expiratory pressures $\left(2 \mathrm{~cm} \mathrm{H} \mathrm{H}_{2} \mathrm{O}\right)$. The lung weight change was recorded by a force-displacement transducer (Model FTO3C; Grass Technologies). All lung preparations underwent a 10-min equilibration perfusion to establish isogravimetric conditions followed by a 30-min step change in perfusate albumin concentration $(\mathrm{g} / 100 \mathrm{ml})$ of albumin from 0 to 10. In some cases, AP-CSD (final concentration of $10 \mathrm{\mu M}$ ) was added into the high-albumin perfusate between minute 20 and 40 from the beginning of perfusion. The fluid filtration rate was obtained by fitting a double exponential growth curve, yo $=a\left(1-e^{-k a}\right)+$ $b\left(1-e^{-k b}\right)$, to the lung weight gain upon removal of albumin. The fast exponential component, which was of relatively low amplitude and coincident with the change of solution, most likely represented the effect of the shift in solution viscosity. The slow exponential component represented fluid filtration across the vessel wall induced by the change in oncotic pressure. The filtration rate was determined from the initial slope of this component extrapolated to zero time.

\section{Statistical analysis}

Data handling was performed using Sigma Plot software (SPSS). For statistical analysis, a paired two-tailed Student's $t$ test was used to compare data between two groups.

\section{Online supplemental material}

Fig. S1 provides a characterization of primary MLVECs. Fig. S2 shows the effect of a Rho inhibitor on phosphorylation of MLC 2 in $\mathrm{Cav}_{-1} 7^{-1-}$ endothelium. Table S1 summarizes the parameters of transvascular fluid filtration across the microvessel wall in isolated lungs. Online supplemental material is available at http://www.jcb.org/cgi/content/full/jcb.201012129/DC1.

We thank Sarah J. Parsons (University of Virginia, Charlottesville, VA) for HAtagged pl90A, p190B, Y1105F, and Y1087F mutants and Klaus Hahn (UNC, Chapel Hill, NC) for the RhoA biosensor.

This work was supported by National Institutes of Health grants RO $1 \mathrm{HL}$ 45638 and POI HL 60678 to A.B. Malik and ROI HL103922 to Y. Komarova

Submitted: 21 December 2010

Accepted: 2 May 2011

\section{References}

Augusto, O., M.G. Bonini, A.M. Amanso, E. Linares, C.C. Santos, and S.L. De Menezes. 2002. Nitrogen dioxide and carbonate radical anion: two emerging radicals in biology. Free Radic. Biol. Med. 32:841-859. doi:10.1016/S0891-5849(02)00786-4

Aulak, K.S., T. Koeck, J.W. Crabb, and D.J. Stuehr. 2004. Dynamics of protein nitration in cells and mitochondria. Am. J. Physiol. Heart Circ. Physiol. 286:H30-H38. doi:10.1152/ajpheart.00743.2003

Beckman, J.S., T.W. Beckman, J. Chen, P.A. Marshall, and B.A. Freeman. 1990. Apparent hydroxyl radical production by peroxynitrite: implications for endothelial injury from nitric oxide and superoxide. Proc. Natl. Acad. Sci. USA. 87:1620-1624. doi:10.1073/pnas.87.4.1620

Bonini, M.G., R. Radi, G. Ferrer-Sueta, A.M. Ferreira, and O. Augusto. 1999. Direct EPR detection of the carbonate radical anion produced from peroxynitrite and carbon dioxide. J. Biol. Chem. 274:10802-10806. doi: $10.1074 / j b c .274 .16 .10802$

Bonini, M.G., R.P. Mason, and O. Augusto. 2002. The mechanism by which 4-hydroxy-2,2,6,6-tetramethylpiperidene-1-oxyl (tempol) diverts peroxynitrite decomposition from nitrating to nitrosating species. Chem. Res. Toxicol. 15:506-511. doi:10.1021/tx015571z

Brovkovych, V., L.W. Dobrucki, S. Brovkovych, I. Dobrucki, C.A. Do Nascimento, A. Burewicz, and T. Malinski. 1999. Nitric oxide release from normal and dysfunctional endothelium. J. Physiol. Pharmacol. 50:575-586.

Bucci, M., J.P. Gratton, R.D. Rudic, L. Acevedo, F. Roviezzo, G. Cirino, and W.C. Sessa. 2000. In vivo delivery of the caveolin-1 scaffolding domain inhibits nitric oxide synthesis and reduces inflammation. Nat. Med. 6:1362-1367. doi:10.1038/82176

Cain, R.J., B. Vanhaesebroeck, and A.J. Ridley. 2010. The PI3K p110alpha isoform regulates endothelial adherens junctions via Pyk2 and Rac1. J. Cell Biol. 188:863-876. doi:10.1083/jcb.200907135

Chang, J.H., S. Gill, J. Settleman, and S.J. Parsons. 1995. c-Src regulates the simultaneous rearrangement of actin cytoskeleton, p190RhoGAP, and p120RasGAP following epidermal growth factor stimulation. J. Cell Biol. 130:355-368. doi:10.1083/jcb.130.2.355 
Corada, M., M. Mariotti, G. Thurston, K. Smith, R. Kunkel, M. Brockhaus, M.G. Lampugnani, I. Martin-Padura, A. Stoppacciaro, L. Ruco, et al. 1999. Vascular endothelial-cadherin is an important determinant of microvascular integrity in vivo. Proc. Natl. Acad. Sci. USA. 96:98159820. doi:10.1073/pnas.96.17.9815

Dimmeler, S., I. Fleming, B. Fisslthaler, C. Hermann, R. Busse, and A.M. Zeiher. 1999. Activation of nitric oxide synthase in endothelial cells by Aktdependent phosphorylation. Nature. 399:601-605. doi:10.1038/21224

García-Cardeña, G., P. Martasek, B.S. Masters, P.M. Skidd, J. Couet, S. Li, M.P. Lisanti, and W.C. Sessa. 1997. Dissecting the interaction between nitric oxide synthase (NOS) and caveolin. Functional significance of the nos caveolin binding domain in vivo. J. Biol. Chem. 272:25437-25440. doi:10 .1074/jbc.272.41.25437

Garrean, S., X.P. Gao, V. Brovkovych, J. Shimizu, Y.Y. Zhao, S.M. Vogel, and A.B. Malik. 2006. Caveolin-1 regulates NF-kappaB activation and lung inflammatory response to sepsis induced by lipopolysaccharide. J. Immunol. 177:4853-4860.

Gonzalez, E., A. Nagiel, A.J. Lin, D.E. Golan, and T. Michel. 2004. Small interfering RNA-mediated down-regulation of caveolin-1 differentially modulates signaling pathways in endothelial cells. J. Biol. Chem. 279: 40659-40669. doi:10.1074/jbc.M407051200

Görg, B., N. Qvartskhava, P. Voss, T. Grune, D. Häussinger, and F. Schliess. 2007. Reversible inhibition of mammalian glutamine synthetase by tyrosine nitration. FEBS Lett. 581:84-90. doi:10.1016/j.febslet.2006.11.081

Gow, A.J., D. Duran, S. Malcolm, and H. Ischiropoulos. 1996. Effects of peroxynitrite-induced protein modifications on tyrosine phosphorylation and degradation. FEBS Lett. 385:63-66. doi:10.1016/0014-5793(96)00347-X

Grande-García, A., A. Echarri, J. de Rooij, N.B. Alderson, C.M. WatermanStorer, J.M. Valdivielso, and M.A. del Pozo. 2007. Caveolin-1 regulates cell polarization and directional migration through Src kinase and Rho GTPases. J. Cell Biol. 177:683-694. doi:10.1083/jcb.200701006

Grune, T., I.E. Blasig, N. Sitte, B. Roloff, R. Haseloff, and K.J. Davies. 1998. Peroxynitrite increases the degradation of aconitase and other cellular proteins by proteasome. J. Biol. Chem. 273:10857-10862. doi:10.1074/jbc 273.18.10857

Hoffman, A., S. Goldstein, A. Samuni, J.B. Borman, and H. Schwalb. 2003. Effect of nitric oxide and nitroxide SOD-mimic on the recovery of isolated rat heart following ischemia and reperfusion. Biochem. Pharmacol. 66:1279-1286. doi:10.1016/S0006-2952(03)00441-6

Holinstat, M., N. Knezevic, M. Broman, A.M. Samarel, A.B. Malik, and D. Mehta. 2006. Suppression of RhoA activity by focal adhesion kinaseinduced activation of p190RhoGAP: role in regulation of endothelial permeability. J. Biol. Chem. 281:2296-2305. doi:10.1074/jbc.M511248200

Jaffrey, S.R., and S.H. Snyder. 2001. The biotin switch method for the detection of S-nitrosylated proteins. Sci. STKE. 2001:pl1. doi:10.1126/stke.2001 86.pl1

Jourd'heuil, D., F.L. Jourd'heuil, P.S. Kutchukian, R.A. Musah, D.A. Wink, and M.B. Grisham. 2001. Reaction of superoxide and nitric oxide with peroxynitrite. Implications for peroxynitrite-mediated oxidation reactions in vivo. J. Biol. Chem. 276:28799-28805. doi:10.1074/jbc.M102341200

Knezevic, N., A. Roy, B. Timblin, M. Konstantoulaki, T. Sharma, A.B. Malik, and D. Mehta. 2007. GDI-1 phosphorylation switch at serine 96 induces RhoA activation and increased endothelial permeability. Mol. Cell. Biol. 27:6323-6333. doi:10.1128/MCB.00523-07

Komarova, Y.A., A.S. Akhmanova, S. Kojima, N. Galjart, and G.G. Borisy. 2002. Cytoplasmic linker proteins promote microtubule rescue in vivo. J. Cell Biol. 159:589-599. doi:10.1083/jcb.200208058

Lima, B., M.T. Forrester, D.T. Hess, and J.S. Stamler. 2010. S-nitrosylation in cardiovascular signaling. Circ. Res. 106:633-646. doi:10.1161/ CIRCRESAHA.109.207381

Mammoto, T., S.M. Parikh, A. Mammoto, D. Gallagher, B. Chan, G. Mostoslavsky, D.E. Ingber, and V.P. Sukhatme. 2007. Angiopoietin-1 requires p190 RhoGAP to protect against vascular leakage in vivo. J. Biol. Chem. 282:23910-23918. doi:10.1074/jbc.M702169200

Mehta, D., and A.B. Malik. 2006. Signaling mechanisms regulating endothelial permeability. Physiol. Rev. 86:279-367. doi:10.1152/physrev.00012 2005

Michel, C.C. 1996. Transport of macromolecules through microvascular walls. Cardiovasc. Res. 32:644-653.

Minshall, R.D., C. Tiruppathi, S.M. Vogel, and A.B. Malik. 2002. Vesicle formation and trafficking in endothelial cells and regulation of endothelial barrier function. Histochem. Cell Biol. 117:105-112. doi:10.1007/ s00418-001-0367-x

Miyawaki-Shimizu, K., D. Predescu, J. Shimizu, M. Broman, S. Predescu, and A.B. Malik. 2006. siRNA-induced caveolin-1 knockdown in mice increases lung vascular permeability via the junctional pathway. Am. $J$. Physiol. Lung Cell. Mol. Physiol. 290:L405-L413. doi:10.1152/ajplung .00292 .2005
Motley, E.D., K. Eguchi, M.M. Patterson, P.D. Palmer, H. Suzuki, and S. Eguchi. 2007. Mechanism of endothelial nitric oxide synthase phosphorylation and activation by thrombin. Hypertension. 49:577-583. doi:10.1161/01 .HYP.0000255954.80025.34

Nitta, T., M. Hata, S. Gotoh, Y. Seo, H. Sasaki, N. Hashimoto, M. Furuse, and S. Tsukita. 2003. Size-selective loosening of the blood-brain barrier in claudin-5-deficient mice. J. Cell Biol. 161:653-660. doi:10.1083/ jcb. 200302070

Patterson, C.E., R.A. Rhoades, and J.G. Garcia. 1992. Evans blue dye as a marker of albumin clearance in cultured endothelial monolayer and isolated lung. J. Appl. Physiol. 72:865-873.

Pertz, O., L. Hodgson, R.L. Klemke, and K.M. Hahn. 2006. Spatiotemporal dynamics of RhoA activity in migrating cells. Nature. 440:1069-1072. doi:10.1038/nature04665

Rajasingh, J., E. Lambers, H. Hamada, E. Bord, T. Thorne, I. Goukassian, P. Krishnamurthy, K.M. Rosen, D. Ahluwalia, Y. Zhu, et al. 2008. Cell-free embryonic stem cell extract-mediated derivation of multipotent stem cells from NIH3T3 fibroblasts for functional and anatomical ischemic tissue repair. Circ. Res. 102:e107-e117. doi:10.1161/ CIRCRESAHA.108.176115

Roof, R.W., M.D. Haskell, B.D. Dukes, N. Sherman, M. Kinter, and S.J. Parsons. 1998. Phosphotyrosine (p-Tyr)-dependent and -independent mechanisms of p190 RhoGAP-p120 RasGAP interaction: Tyr 1105 of p190, a substrate for c-Src, is the sole p-Tyr mediator of complex formation. Mol. Cell. Biol. 18:7052-7063.

Santos, C.X., M.G. Bonini, and O. Augusto. 2000. Role of the carbonate radical anion in tyrosine nitration and hydroxylation by peroxynitrite. Arch. Biochem. Biophys. 377:146-152. doi:10.1006/abbi.2000.1751

Schubert, W., P.G. Frank, S.E. Woodman, H. Hyogo, D.E. Cohen, C.W. Chow, and M.P. Lisanti. 2002. Microvascular hyperpermeability in caveolin-1 (-/-) knock-out mice. Treatment with a specific nitric-oxide synthase inhibitor, L-NAME, restores normal microvascular permeability in Cav-1 null mice. J. Biol. Chem. 277:40091-40098. doi:10.1074/jbc.M205948200

Song, L., S. Ge, and J.S. Pachter. 2007. Caveolin-1 regulates expression of junction-associated proteins in brain microvascular endothelial cells. Blood. 109:1515-1523. doi:10.1182/blood-2006-07-034009

Tatsis, N., D.A. Lannigan, and I.G. Macara. 1998. The function of the p190 Rho GTPase-activating protein is controlled by its N-terminal GTP binding domain. J. Biol. Chem. 273:34631-34638. doi:10.1074/jbc.273.51.34631

Thibeault, S., Y. Rautureau, M. Oubaha, D. Faubert, B.C. Wilkes, C. Delisle, and J.P. Gratton. 2010. S-nitrosylation of beta-catenin by eNOS-derived NO promotes VEGF-induced endothelial cell permeability. Mol. Cell. 39:468-476. doi:10.1016/j.molcel.2010.07.013

Vincent, S., and J. Settleman. 1999. Inhibition of RhoGAP activity is sufficient for the induction of Rho-mediated actin reorganization. Eur. J. Cell Biol. 78:539-548.

Vogel, S.M., J. Orrington-Myers, M. Broman, and A.B. Malik. 2006. De novo ICAM-1 synthesis in the mouse lung: model of assessment of protein expression in lungs. Am. J. Physiol. Lung Cell. Mol. Physiol. 291:L496L501. doi:10.1152/ajplung.00353.2005

Wildenberg, G.A., M.R. Dohn, R.H. Carnahan, M.A. Davis, N.A. Lobdell, J Settleman, and A.B. Reynolds. 2006. p120-catenin and p190RhoGAP regulate cell-cell adhesion by coordinating antagonism between Rac and Rho. Cell. 127:1027-1039. doi:10.1016/j.cell.2006.09.046

Zhao, Y.Y., Y.D. Zhao, M.K. Mirza, J.H. Huang, H.H. Potula, S.M. Vogel, V. Brovkovych, J.X. Yuan, J. Wharton, and A.B. Malik. 2009. Persistent eNOS activation secondary to caveolin-1 deficiency induces pulmonary hypertension in mice and humans through PKG nitration. J. Clin. Invest. 119:2009-2018. doi:10.1172/JCI33338 